\title{
Trayectoria de las relaciones entre empresas forestales y comunidades mapuche en Chile Aportes para la reconstrucción etnográfica del desarrollo económico en contextos interétnicos
}

\author{
Noelia Carrasco H. \\ Universidad de Concepción, Concepción, Chile. Email: noeliacarrasco@udec.cl
}

\begin{abstract}
Resumen: En los últimos quince años, en el territorio centro sur de Chile se evidencia una gama de situaciones que definen a las relaciones entre empresas forestales y comunidades mapuche a partir de principios de tensión, confrontación, atisbos de diálogo, e incluso, acuerdos de trabajo conjunto. En el marco de estos procesos, se ha puesto de manifiesto la plasticidad de los posicionamientos tanto de las comunidades, como también de las empresas que han debido situarse desde nuevas coordenadas jurídicas y ético - políticas con respecto a las comunidades indígenas. Al respecto, cobra especial importancia lo que sucede en Chile con la entrada en vigencia del Convenio 169 de la OIT y las transformaciones que esto implica en relación a las disposiciones y normativas que afectan a las empresas que invierten en estos territorios y su relación con las comunidades indígenas. Éstas, por su parte, también experimentan su propio proceso de replanteamiento ante las nuevas condiciones políticas y económicas que les atañen y que se van definiendo en la política indígena nacional. Este artículo, ofrece una descripción de las formas y contenidos que condicionan a la relación entre empresas forestales y comunidades mapuche en Chile durante los últimos 15 años, incluyendo hechos y desafíos transversales. Se examina la pertinencia de las aplicaciones etnográficas a las expresiones del desarrollo económico en contextos interétnicos y se concluye en torno a los roles que tanto las ciencias sociales como los propios actores implicados en los procesos de desarrollo vienen asumiendo en el último periodo.
\end{abstract}

Palabras clave: análisis etnográfico, comunidades mapuche, empresas forestales

\section{History of relations between forestry companies and Mapuche communities in Chile. Contributions to the ethnographic reconstruction of economic development in interethnic contexts}

\begin{abstract}
During the last fifteen years, in the central-south area of Chile, there is evidence of a broad set of situations that define the relationship between Mapuche communities and forestry companies. These situations range from tension and confrontation to glimpses of dialogue, and even cooperation arrangements. In the framework of these processes, the plasticity of the positions of both communities and companies has been highlighted. Also both positions had to be placed within new legal and ethic-politic coordinates in relationship with indigenous people. In this regard, Chilean signature of the ILO 169 and the changes that this implies to the regulations affecting the relationship between businesses and indigenous communities, are particularly important. Indigenous communities, in turn, also undergo their own rethinking process facing the new political and economic conditions that affect them, as well as national indigenous policy. This article provides an overview of the forms and contents that affect the relationship between forestry companies and the mapuche people in Chile during the last fifteen years, including facts and cross challenges. It examines the relevance of ethnographic applications about expressions of economic development in inter-ethnic contexts, and concludes around the roles that both social sciences and actors involved in development processes are assuming in the last period.
\end{abstract}

Key words: ethnographic analysis, Mapuche communities, forestry companies

\section{História das relações entre empresas florestais e comunidades Mapuche no Chile. Contribuições para a reconstrução etnográfica do desenvolvimento econômico em contextos étnicos}

\footnotetext{
Resumo: Nos últimos quinze anos no território sul-central do Chile há uma série de situações que definem as relações entre empresas florestais e comunidades mapuches como de tensão, confrontação, vislumbres de diálogo, e até mesmo acordos trabalhando juntos. Como parte desses processos tem demonstrado a plasticidade das posições de ambas as comunidades, bem como as empresas que tiveram ter consideração de novas coordenadas legaia, éticas e políticas para as comunidades indígenas. A este respeito, é particularmente importante o que acontece no Chile, com a entrada em vigor da Convenção 169 da OIT e as mudanças que isso implica em relação às regras e regulamentos que afetam as empresas que investem nestes territórios e sua relação com comunidades indígenas. Estes, por sua vez, também passam por seu
} 
próprio processo de repensar a novas condições políticas e econômicas que os afetam e de ser definido na política indigenista nacional. Este artigo fornece uma visão geral das formas e conteúdos que determinam a relação entre empresas florestais e comunidades Mapuche no Chile durante os últimos 15 anos, incluindo fatos e desafios transversais. Ele examina a relevância de aplicações etnográficos para expressões de desenvolvimento econômico em contextos étnicos e conclui em torno dos papéis que tanto as ciências sociais e os atores envolvidos nos processos de desenvolvimento estão assumindo no último período.

Palavras-chave: análise etnográfica, comunidades mapuches, empresas florestais

$$
* * *
$$

\section{Introducción}

El presente artículo constituye un producto de la investigación etnográfica denominada "Estudio comparativo de las relaciones entre empresas forestales y comunidades mapuche en la región de la Araucanía.

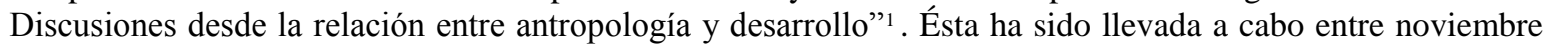
de 2008 y noviembre de 2010, e incluyó fases de trabajo de campo y sistematización de material teórico. El contexto de esta investigación antropológica lo constituye un territorio determinado por la tensión derivada de la ocupación violenta y forzada, que da como resultado la soberanía del Estado nación chileno en el territorio previamente vivido por el pueblo mapuche, en sus diversas expresiones identitarias ${ }^{2}$. A un siglo de este acontecimiento, y tras importantes transformaciones en la relación entre el Estado y el pueblo mapuche, las políticas económicas en Chile han abierto el mapa sociocultural a un nuevo actor clave en el territorio, el gran empresario privado. Así las cosas, hoy en día la relación entre las empresas forestales y las comunidades mapuche en Chile constituyen un objeto de conocimiento, que puede permitir avanzar en procesos sistemáticos de observación, interacción, participación y análisis de hechos y situaciones que han marcado y condicionado las relaciones interétnicas en el territorio de La Araucanía. La investigación realizada ha posibilitado identificar hitos y caracterizar la relación estudiada, partiendo de la premisa que se trata de una relación multiversada - es decir, que posee varias expresiones y versiones, además de contar con diversas lecturas que la marcan al mismo tiempo, como una relación política y económicamente clave en el contexto nacional e internacional.

En el transcurso de esta investigación antropológica, ha sido posible identificar aspectos de tipo local o situacional, que reflejan las características y los cambios de esta relación en Chile en el último tiempo. Esto permite iniciar la discusión desde un prisma diacrónico, que nos remitirá al contexto de los hechos para comprender su sentido y lugar en el marco de la historia de esta relación particular.

\section{Materiales y métodos}

\section{Contexto Socio-histórico}

Si consideramos las relaciones entre empresas forestales y comunidades mapuche en Chile, se pueden distinguir varios hitos y etapas. Ya en 1998, la relación entre empresas forestales y comunidades mapuche se constituye como un tema socialmente reconocido y políticamente controversial en el país, que comienza a interesar a sectores sociales, políticos, económicos, y a las propias ciencias sociales. A continuación, se exponen algunos hitos que permiten comprender la naturaleza de la relación estudiada.

Económicamente, Chile vive desde 1973 la institucionalización de formas y contenidos propios de un neoliberalismo experimental conducido por la dictadura militar, entendido a partir de la implementación de medidas radicales para reordenar el esquema económico - productivo propiciado por el gobierno socialista de Salvador Allende. En este neoliberalismo, el Estado se va transformando en un actor cada vez más reducido en su presencia económica, proceso marcado por el progresivo avance de la privatización de los recursos y de los sistemas de administración de la salud, la educación, las comunicaciones, los sistemas viales, la desprotección de la industria nacional y la liberalización de los flujos comerciales y de capital, entre otros. Esto tiene a su vez injerencia en las brechas socioeconómicas en el país y permite configurar un mapa sociológico en que el mundo privado, representado por las empresas - los empresarios - y sus prácticas productivas e impactos sociales, adquiere un importante protagonismo en la escena societal nacional. 
Las comunidades mapuche viven, en la década de los 90 profundos cambios en su ordenamiento jurídico y socioeconómico. Tanto la implementación de la Ley Indígena 19.253 de 1993 como la generación y aplicación de una serie de instrumentos institucionales - programas y proyectos gubernamentales y de ONG's- para promover el desarrollo de los pueblos indígenas, pueden ser considerados como dos grandes motores de las condiciones en que efectivamente se encuentra la población mapuche de Chile en las tres últimas décadas.

Las transformaciones políticas suscitadas en Chile durante los gobiernos de la Concertación, dan lugar a la aparición pública y a la apropiación sociocultural de una serie de temas, actores y problemáticas sociales nuevas, que condicionan todo el escenario sociopolítico del país. Entre estos temas se encuentran el medio ambiente, las mujeres, la infancia, los jóvenes, los pueblos indígenas, entre otros. Estas categorías son también parte de los lenguajes cotidianos y coloquiales, que abren nuevas posibilidades comunicativas y generan nuevos vértices para el análisis de la vida social - particularmente en lo que concierne a las relaciones interétnicas, identificando a los pueblos indígenas con demandas, derechos y reivindicaciones específicas. Durante esta década entonces, se puede situar el resurgimiento de los pueblos indígenas como tema de debate social y político, rozando las fibras de la identidad - de lo propio y de lo ajeno, que marcan a los estudios antropológicos del derecho.

El proceso anterior, estuvo a su vez marcado por importantes cambios ideológicos, particularmente en lo que concierne a los recursos naturales y su explotación productiva. Específicamente en el rubro de la industria forestal, el año 1974 marca el hito a partir del cual en el país se instala la promoción y el fomento de las plantaciones de especies exóticas, a través de la promulgación del Decreto Ley 701 (Ley de Fomento Forestal, 1974). El principio que sostiene a esta promulgación, procede de la ideología económica imperante, de acuerdo a la cual los recursos naturales son explotables, los suelos deben utilizarse productivamente y la industria de la madera y el papel constituyen focos productivos rentables a gran escala. Se impone de este modo, una racionalidad económica por sobre otra de carácter conservacionista, que inspiraba a las legislaciones forestales previas (Ley de Bosques, 1931). A partir de ello, puede observarse en Chile el surgimiento de un proceso polarizado en lo que a sistemas forestales se refiere: por un lado se mantiene la idea convencional del bosque nativo como un espacio natural a resguardar, y por otro se instala la definición de las plantaciones de especies exóticas como una práctica forestal productiva con fines estrictamente económicos.

Finalmente, el escenario internacional marca un momento especialmente importante para los pueblos indígenas en el mundo. Naciones Unidas, marca para 1995-2005 el denominado primer "Decenio Internacional de las Poblaciones Indígenas", con la meta de "fortalecer la cooperación internacional para la solución de los problemas con que se enfrentaban los pueblos indígenas en esferas tales como los derechos humanos, el medio ambiente, el desarrollo, la educación y la salud". Esto legitimó, bajo diversos ángulos, incluir el tema de los pueblos indígenas y sus derechos en las agendas públicas, y sobre todo, hacerlo parte de las discusiones locales y nacionales sobre derechos y respuesta a sus demandas históricas.

El Gobierno de Chile, y el pueblo mapuche fueron sensibles a las características previamente expuestas, en la medida en que organizaciones y comunidades mapuche vivenciaron espacios de acusación y de reclamación por sus demandas, generando debates políticos relevantes. Se denuncian los primeros ataques incendiarios y las ocupaciones de predios de empresas forestales por parte de comunidades. De esta manera se comprende el inicio, en 1998, de las manifestaciones mediáticamente difundidas en que comunidades mapuche exigían a las empresas forestales la devolución de sus tierras. Estas demandas se sostuvieron en dos grandes razones. Desde el punto de vista de lo que para las comunidades implica la necesidad de tierras para solventar el natural crecimiento de las familias, y desde la respuesta a los impactos negativos que les supone convivir con grandes plantaciones de especies exóticas. Estos dos grandes tipos de problemas constituyen los principales argumentos que sostienen la conocida confrontación entre las comunidades mapuche y las empresas forestales. Estas últimas han establecido plantaciones en territorios que algunas comunidades reivindican como propios, y los sistemas de producción de monocultivos de especies como el pino y el eucaliptus suponen una serie de impactos ambientales y socioculturales que durante este periodo comienzan a denunciar. 
Esta etapa de relaciones entre empresas forestales y comunidades mapuche en Chile, vivida en la última década, se caracteriza como un periodo de confrontación y de exposición de argumentos, basados principalmente en formas distintas de concebir la economía, los recursos naturales y el desarrollo. Considerando que los principales problemas que expusieron las comunidades pueden agruparse en dos demandas de tierras e impactos socioambientales -el periodo fue asumido con diferentes estrategias, tanto desde el aparato público como desde el mundo privado; desde los gobiernos de la coalición denominada Concertación de Partidos por la Democracia- que suceden a la dictadura desde 1990 hasta 2010, con cuatro gobiernos a su haber - y desde las empresas forestales que producen en un territorio históricamente reconocido como indígena.

En el caso del Estado, se observó durante la última década, un tratamiento progresivo desde diversas y contradictorias políticas hacia los pueblos indígenas. Por un lado, se invirtió en implementar una serie de programas que pretendieron promover el desarrollo económico y social de los pueblos indígenas, desde medidas tales como establecer el tema a nivel transversal en el concierto de las políticas públicas (junto a otros como el género y la protección del medio ambiente) hasta la ejecución efectiva - aunque no exenta de juicios y de acusaciones de malversación - del Fondo de Tierras Indígenas. Este último, instrumento definido en la Ley Indígena 19.253, permitió -especialmente en el caso mapuche- ir dando respuesta a algunas de las demandas por la recuperación de tierras impuestas por comunidades. De esta manera, desde la perspectiva oficial del desarrollo del pueblo mapuche, "se dio respuesta a la necesidad sentida de contar con mayores extensiones para resolver la reproducción económica y social de las unidades domésticas; que nuevos matrimonios contaran con su legítimo espacio para vivir y producir, y que las nuevas generaciones puedan proyectarse material y simbólicamente en un territorio" 3 . Por otra parte, la necesidad de acoplar a la entrega de tierras un programa de apoyo para el desarrollo económico y productivo, fue prontamente sentida por muchas comunidades. Y la respuesta gubernamental estuvo ciertamente basada en discursos relativos a visiones integrales del desarrollo, materializadas principalmente a través de la macro iniciativa gubernamental denominada Programa Orígenes ${ }^{4}$. Esta iniciativa constituye una de las principales propuestas de desarrollo de parte de los dos últimos gobiernos de la Concertación hacia los pueblos indígenas en Chile. Pero en otro sentido, hubo también una reacción estatal fuertemente represiva y criminalizante de la demanda indígena, pues además de esta promoción del desarrollo indígena, se procedió también con medidas de confrontación enmarcadas en la imagen de "actos delictuales, actos de violencia". Se justificó el tratamiento penal de acciones derivadas de procesos de demanda y reivindicación de tierras y de recursos para el desarrollo ${ }^{5}$. Esta doble actitud de los gobiernos de la Concertación hacia las comunidades mapuche, mantuvo el periodo en un constante vaivén de acciones tanto de valoración como de condena, decoradas con una retórica desarrollista que mantuvo su norte en la generación de las condiciones para el desarrollo económico y productivo del territorio. A partir de ello, se promovieron y financiaron iniciativas productivas y comerciales, que constituyeron en alguna medida una respuesta a la necesidad de medios para el desarrollo. No obstante, las medidas represivas se mantuvieron durante todo el periodo, dejando a 2010 un total de 3 personas mapuche muertas en enfrentamientos con la policía en territorios en litigio, decenas de mapuche llevados a tribunales de justicia, muchos de los cuales hoy se encuentran cumpliendo condenas en cárceles del país.

\section{Indicios de una nueva etapa}

Mientras el Estado y las comunidades se relacionaban bajo las coordenadas políticas y jurídicas anteriormente descritas, la empresa privada presente con inversión en el territorio mapuche vive su propio proceso de participación y cambio. Durante toda la década comprendida entre 1998 y 2008, las empresas forestales mantuvieron su señal de alerta encendida en la zona, asumiendo que su presencia y actividades en el territorio constituían blanco de demandas y reivindicaciones mapuche. Desde sus matrices ideológicas y operativas, algunas empresas avanzaron en sus iniciativas inspiradas por la responsabilidad social empresarial, mientras que otras identificaron campos y mecanismos para mantener una presencia vigente sin exponerse a conflictos en el territorio. Otras en tanto, fueron sofisticando un rol para gubernamental, diseñando y ofreciendo programas especialmente dirigidos a la forestación con especies nativas en predios mapuche. Lo cierto es que se trató de una década en que la industria forestal estuvo especialmente marcada por los movimientos en la propiedad (principalmente fusiones que aumentan la concentración del patrimonio en grandes empresas) y la escala productiva. De acuerdo a Camus "para el año 2000 las exportaciones de productos forestales alcanzaron una cifra record al registrar envíos por US\$2.400.000.000, aumentándose en 
$23 \%$ respecto al año anterior. Se proyectaba asimismo que la producción registraría un aumento de 3,5\% el año 2001, a causa de los nuevos proyectos de inversión en tableros, madera aserrada y celulosa" (Camus 2006: 341). En este mismo sentido, otro estudio señala que "durante la década de los 90, el sector forestal se consolidó como el segundo sector de la economía, detrás de la minería, siempre basado en las plantaciones...en el período 1991-1995 las inversiones en el sector alcanzaron los 2.440 millones de dólares, estimándose que se adicionen 3.500 millones de dólares en el período 1996-2002 y las exportaciones después de alcanzar en 1995 su récord de 2.369 millones de dólares sumaron en 1997 los 1.829,9 millones" (Bordeu 1998: 2). Este mismo autor, en relación a la tenencia de los recursos forestales en Chile, y considerando la importancia productiva y comercial del pino radiata y el eucaliptus, indica que "solo las empresas del Grupo Arauco y Grupo CMPC concentran el 31,7 y 18, 9\% de la superficie plantada, superando entre ambas el 50\%. Para el caso de eucalipto el patrimonio se encuentra más distribuido no superando ninguna empresa el 10\% de la superficie total" (op. cit., Pág. 4). Ante el mismo tema, se refirma la siguiente estructura de la propiedad de las plantaciones forestales en Chile: 78\% Gran Propietario, 18\% Mediano y 4\% Pequeño (Leyton, 2009). Este antecedente cobra sentido, si consideramos que el patrimonio de las empresas forestales se encuentra principalmente en las regiones con mayor concentración de población mapuche rural (regiones del Bio Bio, Araucania, Los Ríos y Los Lagos) (Catalán, 2007).

Considerando lo expuesto, las principales empresas forestales del territorio, impulsaron a su vez programas y acciones tendientes a "favorecer una mejor inserción en la comunidad... surge al interior de la empresa la conciencia del lugar que ellos ocupan y cuál puede ser su incidencia en la vida de las comunidades mapuches vecinas" (Wigodski 2007: 6). Dentro de estas iniciativas empresariales, se reconocen diversas expresiones del modo en que al interior de las empresas se va concibiendo y decidiendo las formas de operar en relación a los mapuche. Desde el punto de vista antropológico, lo más interesante en este contexto es identificar los nuevos significados y categorías que ilustran el modo en que esta otra población es concebida por parte de actores del contexto empresarial, las maneras en que sus demandas son interpretadas y el sentido finalmente asignado a su posición en el proceso. Podemos reconocer, a partir de la revisión etnográfica aplicada sobre este periodo, que para producir tales transformaciones en las empresas se conjugaron factores de índole sociocultural, eco-político, jurídico y económico; todos ellos, asociados y sutilmente articulados a través de posturas públicas y de la justificación a las iniciativas emprendidas. Un primer aspecto clave, era transferir al Estado la jurisprudencia en todos los actos que implicaban atentados contra la propiedad, en los cuales las empresas ocupaban el rol de víctima. De esta manera, las empresas no lo juegan de modo desprotegido el rol acusador sino que en todos los casos, lo hacen reafirmados en las acusaciones que la Fiscalía establecía contra mapuche inculpados. Esta situación, llevó a que el movimiento social compuesto por organizaciones indígenas y diversos organismos y personas que "adhieren a la causa mapuche", encabezados por actores claves en su condición de stakeholders, acusaran muchas veces al Gobierno de complicidad con las empresas, de ser guardianes de su patrimonio e intereses, descuidando de esta forma su compromiso para con los pueblos indígenas y la protección de sus derechos.

Al margen de los focos de conflicto y la evidente tensión social ocasionada por los antecedentes previamente expuestos - vivida principalmente en la región de La Araucanía, las empresas forestales con mayor patrimonio en el territorio, desarrollaban acciones definidas desde sus horizontes de sentido como "acciones de buena vecindad". En lo aparente, estas acciones daban cuenta de cierto reconocimiento por parte de las empresas, de las condiciones de pobreza y exclusión en que efectivamente se encuentran sus "vecinos mapuche". Es así, como durante este periodo pudimos evidenciar la ejecución de programas de apoyo educativo (entrega de materiales a escuelas públicas ubicadas en comunidades, becas para estudiantes), programas de capacitación (dirigidos a incentivar actividades productivas en las zonas rurales) y otros programas de tipo social (apoyo a clubes deportivos) que buscaron poner de manifiesto la presencia de las empresas más allá de la actividad meramente productiva. Además de ello, se pudo dar cuenta de diversas reacciones de parte de las empresas ante la situación de las comunidades mapuche, sobre todo al reconocer que sus demandas y reivindicaciones tenían efectivamente que ver con su patrimonio y con el éxito o fracaso de sus actividades productivas en éste. Surgieron de este modo, una serie de cambios que daban cuenta de una sutil transformación en los cánones de la cultura empresarial, que respondían - quizá - a la necesidad de comprender de nuevos y mejores modos la "situación mapuche".

Se inicia así el año 2008 y comienzan a suscitarse una serie de nuevas expresiones en la relación entre empresas forestales y comunidades mapuche. Recogiendo algunos ensayos que el gobierno había 
intencionado desde las fusiones entre programas previos y el referido Programa Orígenes, cobran lugar propuestas como el Modelo Forestal Intercultural. Este constituye un referente importante, que a partir de 2005 comienza a ser difundido en el marco de los "nuevos enfoques en la gestión y manejo de recursos naturales en tierras mapuche" (Conaf, noviembre de 2005). El germen de este modelo forestal intercultural, se encuentra en la validación que el gobierno de Chile - a través de la CONAF $^{6}$ - hace de aspectos de la cosmovisión mapuche en torno al bosque y los recursos naturales asociados a su producción (agua y suelo, principalmente). Este modelo, se propuso organizar la distribución de los recursos asignados para el desarrollo económico, social y culturalmente sustentable de las comunidades indígenas. A través de proyectos que integrasen dimensiones ecológicas y culturales, las comunidades podrían optar a recursos para, por ejemplo, proteger fuentes de agua, cercar espacios sagrados, entre otros. De acuerdo a las fuentes revisadas, a 2008 se financiaron un total de 85 iniciativas que respondieron a los principios del Mofin (registrado por CONAF como MOFIM - Modelo Forestal Intercultural Mapuche). Estos proyectos contemplaron metas económicas y culturales, todas ellas asociadas tanto a la protección o promoción del bosque nativo como a la forestación con especies amigables con los ecosistemas locales.

En concordancia con lo anterior, algunas empresas comienzan a modificar su accionar dirigido hacia las comunidades mapuche. La "buena vecindad" en tanto modelo para diseñar y organizar las relaciones entre empresas y comunidades, comienza a ser evaluada como una iniciativa asistencialista, ante lo cual el Estado va promoviendo considerar la cosmovisión mapuche. Por ejemplo, una de las grandes empresas forestales, convoca la asesoría del experto mapuche que previamente había contribuido a CONAF en el diseño del modelo forestal intercultural. Se inicia entonces un nuevo momento en las relaciones entre empresas forestales y comunidades mapuche, marcado por la utilización de nuevos lenguajes corporativos -desde las empresas-, coyunturas económicas que propician acercamientos y requerimientos jurídicos que fuerzan predisposiciones al diálogo ya a un nuevo tipo de reconocimiento entre las partes implicadas.

En efecto, se constata en los últimos tres años en Chile, la puesta en escena de nuevas formas y sentidos en las relaciones entre empresas forestales y comunidades mapuche. En consideración a las variables ético sociales, económicas y jurídicas, las grandes empresas formularon acercamientos en pos de resguardar siempre los estándares de la responsabilidad social empresarial, incluyendo aquellos temas presentes en las agendas relativos al cuidado del medio ambiente y el manejo de los impactos operacionales de las faenas forestales. Para el bienio 2008 - 2009, se pone de manifiesto un indicio de giro provocado precisamente por el cambio en las condiciones estructurales de la relación entre empresas y comunidades: muchas comunidades mapuche ya han recuperado tierras - debido a la ejecución del Fondo de Tierras y Aguas administrado por CONADI - por tanto, poseen recursos para producir, y se concreta la ratificación del Convenio 169 de la Organización Internacional del Trabajo en el país.

El nuevo escenario se ve reafirmado, por la importancia que progresivamente cobran los sistemas de certificación forestal que contemplan de forma preponderante la revisión de las condiciones y mecanismos establecidos por las empresas para la vinculación y protección de los derechos de los pueblos indígenas. Si bien en Chile varias empresas han conseguido el sello de certificación FSC o PEFC ${ }^{7}$, como éstas son reevaluadas cada cinco años, condicionan en el futuro la situación a nuevos requisitos internacionales y al cumplimiento de verificadores tanto en materias ambientales como sociales (incluyendo entre estas últimas las relaciones laborales y los vínculos con comunidades vecinas).

El escenario actual, es por tanto, claramente diferente del que se presentaba hace tres años atrás. Las circunstancias jurídicas y económicas han llevado a que algunos emblemáticos liderazgos indígenas modifiquen el tono de confrontación y se hagan parte de conversaciones y negociaciones propias de este nuevo momento. Si tuviésemos que sintetizar el sentido de esta nueva fase, podríamos decir que las empresas forestales han debido reconocer en las comunidades mapuche a un sector relevante desde el punto de vista económico y productivo - sea porque obstaculizan la normalidad de las faenas productivas, sea porque tiene derechos que les exigen consideraciones en el ámbito de su vinculación con el medio y la empleabilidad. A partir de ello, algunas empresas han declarado intenciones y apuestas por establecer nuevas modalidades de relación con las comunidades que les eximan del riesgo a ser cuestionados en sus prácticas productivas y les permitan actuar como "agentes de desarrollo" en los territorios. Como expresión de esto último, tenemos hoy en día la creación de asociaciones de personas mapuche que desean integrarse a las redes del mercado 
exportador, contando con el respaldo de grandes empresarios de la región entre los cuales figuran, las grandes empresas forestales.

Finalmente, la ratificación del Convenio 169 en $\mathrm{Chile}^{8}$, marca un nuevo hito determinante en la relación analizada. En equivalencia con los principios de los sistemas de certificación internacional, el Convenio 169 establece una serie de nuevas condicionantes que afectan a los procedimientos de las empresas, específicamente en lo que concierne a: derechos políticos, procedimientos de consulta, los derechos económicos, sociales y culturales - incluyendo aspectos relativos a la seguridad social, la salud y la educación. Se establece de este modo un nuevo escenario para las relaciones, en que el Estado vuelve a jugar un rol de promotor y fiscalizador, en la medida en que le corresponderá velar por el fiel cumplimiento de estos requisitos. Entre las principales preocupaciones que actualmente podemos declarar ante este tipo de procesos, se encuentra la situación interna de las comunidades, los perfiles de los nuevos líderes y las condiciones que puedan hacer de estos procedimientos instrumentos efectivos para el logro de los objetivos propuestos desde las comunidades.

Ciertamente que, los últimos años no han sido propicios para la reflexión identitaria y política al interior de las organizaciones mapuche; muy por el contrario, pocas comunidades han podido sostener sistemas de liderazgos que reflejen simetrías entre sus estructuras tradicionales y las formaciones funcionales. En muchos casos, se han constatado quiebres internos favorecidos precisamente por sistemas de intervención institucional que desconocen los procesos de organización social intra comunitarios. No obstante ello, desde las comunidades se mantiene una alerta sentida por los cambios que este tipo de corpus jurídico les pueda implicar.

\section{Discusión}

En el relato anterior se ponen en evidencia diversos factores destacables desde un punto de vista teórico y metodológico. En primer lugar, abordar la historicidad de las relaciones del desarrollo nos permite comprender la dinamicidad de éstas en el tiempo y en el espacio, identificando los modos en que diferentes actores y diferentes dominios de conocimiento se entrecruzan. El trabajo etnográfico así definido, permite adentrarse en las tensiones políticas y económicas de los contextos en que se construyen las relaciones. Para Arce \& Long, la potencia de este enfoque etnográfico “... lies in fully acknowledging the battlefields of knowledge and power wherein a multiplicity of actor engage in struggles over the meanings and practicalities of livelihoods, values and organising processes" (Arce \& Long 1998:8).

Esto nos lleva necesariamente a las nuevas definiciones de lo local y de los actores que ponen algo en juego en tramas relacionales como las descritas. Compartimos con Bartolomé (1992) la apreciación de que los procesos y programas de desarrollo implican un sistema complejo de grupos e intereses interactuando. A partir de ello, el acercamiento etnográfico va dejando atrás las versiones maniqueas que demonizan o angelizan a los actores, y va promoviendo nuevas lecturas de los órdenes locales, en función de los procesos de cambio que afectan no sólo las condiciones materiales de vida en las comunidades sino también las componentes del sentido común, el perfil de los dirigentes, los contenidos de los proyectos de desarrollo de las propias comunidades.

Los antecedentes presentados confirman que la antropología puede ofrecer una mirada pertinente para abordar analíticamente este tipo de dinámicas. No obstante, la relación entre actores y la transformación de los parámetros para definir las cualidades de las vinculaciones en el marco de los procesos de desarrollo de las comunidades, exigen hoy en día revisar y sofisticar el instrumental metodológico para, en este tipo de contextos, incorporar sistemáticamente etnografías del mundo empresarial y sus proyecciones hacia el mundo

indígena. Asimismo, se requiere avanzar mucho más aun en la revisión de las dicotomías valóricas y conceptuales que marcan los diseños metodológicos de las etnografías de los procesos de desarrollo; está claro que no se trata sólo de víctimas y culpables, de ganadores y vencedores. Los actores movilizan sus posiciones y con ello, dan cuenta de la renovación de sus formas de comprender las condiciones y sus roles en las situaciones del desarrollo. Esto último, exige un uso más recurrente y cada vez más reflexivo de las perspectivas post-estructuralistas para comprender al desarrollo como categoría histórica, incluyendo en este uso, la problematización y discusión de los debates éticos tradicionales relativos al compromiso con las 
comunidades y la defensa de la diversidad cultural. Estos debates, son precisamente los que dan sentido a un adecuado quehacer etnográfico en torno al desarrollo económico, pues evidencian "the importance of the experiential and subjetivity in social life" (Arce \& Long, Ibid.).

Siguiendo el argumento anterior, los nuevos vínculos entre comunidades mapuche y empresas forestales en Chile, constituyen un objeto de conocimiento y una situación social que requieren aplicaciones metodológicas reflexivas. Por un lado, se debe participar del proceso, siguiendo los hechos y las situaciones, aportando con antecedentes y perspectivas que permitan a los actores evitar dar pasos en falso, calibrar la importancia del momento que protagonizan en la historia de la relación. Por otro lado, debemos preservar y cautelar la buena calidad del aporte en tanto perspectiva crítica, desmantelante, inquisidora de los aspectos más decisivos, considerando que se trata de una relación clave dentro del sistema mayor de relaciones interétnicas del territorio centro sur de Chile. Incluyendo el sentido que aporta la antropología aplicada, el estilo etnográfico más apropiado para este tipo de contextos y procesos sería hoy en día el de la etnografía multilocal (multi-sitied), que comienza a preguntarse ya en la década de los 80 por la investigación etnográfica en el contexto histórico y contemporáneo de un sistema mundo en la economía política capitalista, desafiada por establecer cuadros dinámicos y estimular modos de entender y pensar la realidad sociocultural de la cual se forma parte (Marcus 2008). Esta modalidad demuestra que el centro del análisis etnográfico contemporáneo (que no se encuentra en reclamar algún estado cultural previo o su preservación) se encuentra en las nuevas formas culturales derivadas de las situaciones coloniales subalternas (Marcus Ibid.).

Así comprendido el potencial aporte reflexivo de la antropología ante este tipo de procesos, debiésemos promover la aplicación de la perspectiva etnográfica hacia el estudio de aspectos culturales al interior de las empresas y el sector privado de la economía en general. La descripción de las culturas empresariales de la industria forestal en Chile, podría de este modo, contribuir a fundar una línea de investigación en el marco de los estudios antropológicos del desarrollo en el país. Mediante metodologías que integran mecanismos tradicionales como la observación, la entrevista y la revisión documental, con estrategias informáticas como el uso de software para el análisis cualitativo, está siendo posible levantar perfiles de culturas empresariales que responden a características observables y reveladoras de las condiciones que las empresas efectivamente disponen para su vinculación con las comunidades indígenas. Asimismo, durante el último periodo de la investigación referida al inicio del presente artículo, ha sido posible implementar estrategias de tipo participativo, con integrantes - ejecutivos y técnicos - de empresas forestales de la región. En estas actividades, se ha podido recoger aspectos auto-valorados de la cultura al interior y exterior de las empresas, permitiendo visualizar principios, transformaciones y sentidos de la cosmovisión vigente en este contexto.

\section{Conclusiones}

Antes de presentar las principales conclusiones de este artículo, debe señalarse el alcance que estos antecedentes y reflexiones esperan tener, considerando la diversidad de actores y contextos que están en juego en el problema abordado. En primer lugar, cabe destacar que se trata de un trabajo pensado para contribuir al mejor entendimiento de los procesos sociales e interétnicos del territorio sur de Chile. En este sentido, se aspira a construir un aporte en la inteligibilidad de las relaciones sociales como motores del funcionamiento de la vida social, cualitativamente incidentes en los tonos de la convivencia intercultural. En segundo lugar, se espera establecer un puente comunicativo con actores políticos que, desde escenarios públicos, privados y comunitarios están intentando avanzar de manera efectiva en la construcción de nuevos mecanismos de relación, asentados en los valores de la equidad y la justicia social y ambiental. Finalmente, se pretende ilustrar un modo de ejercer la antropología del desarrollo, marcada por la posibilidad de sintetizar los objetivos éticos y políticos - derivados de la necesidad de superar los problemas sociales del desarrollo económico en contextos interétnicos - y los objetivos analíticos y teórico- metodológicos de la antropología como perspectiva especializada en la descripción y el abordaje de procesos económicos complejos.

Dicho lo anterior, este artículo concluye intentando una síntesis entre dos aspectos claves que definen su contenido. Primero, en cuanto al tema u objeto empírico de la discusión, relevando la importancia de que las ciencias sociales ampliemos la atención en los procesos relacionales y de cambio en los escenarios etnopolíticos del desarrollo económico. 
Considerando que los territorios indígenas poseen recursos naturales con alta incidencia en los cauces del desarrollo y que sus poblaciones siguen dentro del rango de población "no desarrollada", los problemas de la tensión interétnica y los choques entre formas de comprender a la economía seguirán asociados a las industrias forestales, acuícolas, mineras, energéticas, entre otras. Todas estas iniciativas económicas y productivas suponen, además de impactos en las formas de vidas locales, la generación de nuevos y sofisticados sistemas de relaciones sociales, definidos a su vez por contenidos socioculturales e identitarios de gran riqueza etnográfica.

Asociado a lo anterior, y como segundo aspectos a concluir, se desprende la merecida atención a los procesos de desaparición o "desestatalización del Estado", por medio de los cuales este es progresivamente despojado de sus atribuciones convencionales (Sánchez Parga 2009). En efecto, se hace cada vez más problemático - para las comunidades sobre todo - entender e interactuar adecuadamente con los organismos estatales. Las transformaciones en el rol y los deberes del Estado para con las comunidades implican la reelaboración por parte de los actores locales de lo que el Estado es y debe hacer con respecto a sus necesidades, problemas y riesgos. Esto se vino expresando progresivamente durante los gobiernos de la Concertación, y actualmente, con un gobierno de derecha, la situación se ha agudizado, pues éste aparece marcadamente cercano al empresariado, y ausente en materia de políticas indígenas. Hoy en día, descubrimos que esta incertidumbre ante el rol del aparato público en frente de problemas y situaciones como las descritas, ha constituido una condición clave para el curso que en definitiva, van adoptando los nuevos sistemas de relación interétnica. En este escenario, el mundo de la empresa privada adquiere nuevas herramientas y poderes para avanzar en la consecución de sus metas, y las comunidades locales se ven enfrentadas a nuevos y mayores desafíos en el ámbito de la organización, la definición de sus proyectos de desarrollo y el uso de sus recursos.

\title{
Notas
}

${ }^{1}$ Proyecto Fondecyt 11080196. Comisión Nacional de Ciencia y Tecnología, Chile.

${ }^{2}$ En las últimas décadas, diversas organizaciones mapuche han expuesto lo que denominan como su "identidad territorial". De acuerdo a éstas, los mapuche se diferenciarían internamente en el actual territorio chileno, entre mapuche lafkenche - asentados en la costa -, mapuche nagche - asentados en el secano interior, mapuche wenteche - asentados en el valle del Río Cautín - y mapuche pehuenche asentados en la cordillera de los Andes. Comparten el idioma mapuzungun, pero con importantes variaciones dialectales.

${ }^{3}$ No obstante, esto sólo ocurrió en algunos casos, quedando una cantidad importante de demandas insatisfechas y otras mal satisfechas (entre estas últimas, destacan casos como los ocurridos en la comuna de Traiguén, donde el organismo responsable - la CONADI (Corporación Nacional de Desarrollo Indígena) - otorga tierras a una comunidad determinada, conociendo la reivindicación que sobre esa misma propiedad posee otra comunidad vecina.

\begin{abstract}
${ }^{4}$ Financiado por préstamos otorgado por el BID al Gobierno de Chile, el Programa Orígenes se ha ejecutado en dos fases: la primera entre los años 2001 y 2006, y la segunda entre los años 2007 y 2011. Incluye a los pueblos Aymara, Atacameños, Quechua y Mapuche, y ha tenido como objetivo central la promoción del desarrollo con identidad, el fortalecimiento de capacidades y la generación de oportunidades, especialmente focalizado en la población indígena rural.

${ }^{5}$ Cabe señalar que los mapuche que fueron sometidos a juicio y que han sido condenados por actos de esta naturaleza, representan también - desde un punto de vista etnográfico - la expresión de una resistencia frustrada, que en muchos casos no llegó a la confrontación violenta pero se mantiene en condición latente. En la comuna de Chol Chol, a 2009, existían comunidades que aún viviendo a pocos kilómetros del radio urbano, llevaban más de 5 años esperando por la solución al problema de la distribución de agua. En sus integrantes se constata angustia y frustración ante la acción de los organismos públicos, abriéndose una especial brecha para nuevas propuestas de vinculación con actores privados del territorio.
\end{abstract}

${ }^{6}$ Corporación Nacional Forestal, dependiente del Ministerio de Agricultura.

${ }^{7}$ Forest Stewardship Council y Programme for the Endorsement of Forest Certification schemes.

${ }^{8}$ Depositado ante la OIT el 15 de septiembre de 2008, promulgado por Decreto N$^{\circ} 236$ de 2 de octubre y publicado en Diario Oficial el 14 octubre 2008; entra en vigencia en septiembre de 2009, a un año del registro de su ratificación.

\section{Bibliografía}


Arce, A. \& N. Long. (1998), "Reconfiguring modernity and development from an anthropological perspective". En: Anthropology, Development and Modernities. Exploring discourses, conuter-tendencies and violece, Arce y Long (eds.). Routledge. U. K. pp. 1-31.

Bartolomé, L. (1992), "O Estrangeiro profissional e a tentacao fáustica: A antropología frente aos programas de desenvolvimento". En: Arantes, Ruben y Grin Debert, Desenvolvimento e direitos humanos: a responsabilidade do antropólogo. Campinas, editora da Unicamp, pp. 163-173.

Bordeu, A. (1998), Panorama del Sector Forestal en Chile. Disponible en:

http://www.inta.gov.ar/concordia/info/Forestales/contenido/pdf/1998/81\%20BordeuIXrevisado.pdf Consultado en junio de 2010 .

Camus, P. (2006), Ambiente, bosques y gestión forestal en Chile. 1541-2005. Centro de Investigaciones Diego Barros Arana. Editorial LOM, Chile.

Catalán, R. (2007), "Políticas Forestales y Derechos Indígenas en Chile”. En: El Gobierno de Lagos, los pueblos indigenas y el "nuevo trato”. Las paradojas de la democracia chilena. Yañez \& Aylwin eds. Ediciones LOM, Chile. pp. 285-301.

Escobar, A. (1996), “Antropología y Desarrollo”. Disponible en:

http://www.unesco.org/issj/rics154/escobarspa.html Consultado en junio de 2010.

Leyton, J. "Tenencia Forestal en Chile". Estudio de Caso. Disponible en: http://www.fao.org/forestry/54367/es/chl/ Consultado en junio de 2010.

Marcus, G. (2008), "El o los fines de la etnografía: del desorden de lo experimental al desorden de lo barroco". En: Revista de Antropología Social, 17. pp. 27 - 48.

Marcus, G (2001), "Etnografía en/del sistema mundo. El surgimiento de la etnografía multilocal". En: Revista Alteridades, 2001.11 (22) Págs. 111 - 127. México.

Sánchez Parga, J. (2009), "El estado del Estado en la actual sociedad de mercado". En Revista Nueva Sociedad N 221, Fundación Friedrich Ebert. Disponible en: http://www.nuso.org/upload/articulos/3612_1.pdf Consultado en junio de 2010.

Widodski, T. (2007), Responsabilidad Social Empresarial: el caso de Forestal Mininco S.A. y comunidades mapuche. Documentos de Trabajo. Serie Gestión $N^{\circ}$ 89. Centro de Gestión (CEGES) Departamento de Ingeniería Industrial Universidad de Chile. Disponible en:

http://www.dii.uchile.cl/ ceges/publicaciones/89\%20ceges\%20TW.pdf Consultado en junio de 2010.

$$
* * *
$$

Recibido: 30.05.2011

Aceptado: 23.11.2011 